\title{
Effect of Location and Angle of Cutoff Wall on Uplift Pressure in Diversion Dam
}

\author{
Behnam Mansuri • Farzin Salmasi • \\ Behrooz Oghati
}

Received: 20 January 2014/ Accepted: 12 May 2014/Published online: 15 July 2014

(C) The Author(s) 2014. This article is published with open access at Springerlink.com

\begin{abstract}
Some facility for the prevention of piping, reducing exit gradient and seepage amount under hydraulic structures, is construction of cutoff wall and drain. Therefore, this study compares the efficiency of cutoff wall on some design parameters in an assumed diversion dam cross-section. For this purpose, different placements of cutoff wall with various angle of inclination were used in the dam foundation. Results of this study showed that minimum uplift pressure happens when cut off wall is in the heel (upstream) of the dam. With fixing of longitudinal cut off wall placement, inclination of cutoff wall respect to the vertical position, results in reducing of uplift pressure. Effect of inclination of cutoff wall in upstream of the dam; respect to vertical position, in reducing of uplift pressure is very high.
\end{abstract}

Keywords Cutoff wall · Exit gradient - Seepage · Uplift pressure

B. Mansuri · F. Salmasi $(\bowtie) \cdot$ B. Oghati

Water Engineering Department, Agricultural Faculty,

University of Tabriz, Tabriz, Iran

e-mail: Salmasi@Tabrizu.ac.ir

B. Mansuri

e-mail: behnam.mansuri@yahoo.com

B. Oghati

e-mail: behroozob@gmail.com

\section{Introduction}

For dams built on permeable soil foundation, the water percolates through the soil and exerts uplift pressures and may carry soil particles with it leading to undermine erosion. Therefore a dam founded on permeable soil has to be designed against uplift and piping. Cutoffs, like sheet piles or concrete curtains, can be provided to reduce uplift and seepage forces resulting in appreciable saving in dimensions of the dam structure.

The water seeping below the hydraulic structure exerts an uplift pressure on the floor. The uplift pressure is maximum at the point just downstream of the hydraulic structure, when water is full up on the upstream side and there is no water on the downstream side. If the thickness of floor is insufficient, its weight would be inadequate to resist the uplift pressure. This may ultimately lead to bursting of the floor, and thus failure of the hydraulic structure may occur. Exit gradient is usually considered as a measure of the effect of the piping phenomenon. Piping occurs if the exit hydraulic gradient at the downstream point approaches the critical hydraulic gradient. The exit gradient is said to be critical when the upward disturbing force on the grain is just equal to the submerged weight of the grain at the exit.

Solutions for various problems have been given by Harr (1962) applying conformal transformation. Ijam (1994) has analyzed seepage below hydraulic structures with an inclined cutoff at downstream end of the 
base of the structure. Construction of deep cutoff in front of the concrete structure of the dam to remedy the developed seepage problems has been discussed and presented by Di Cervia (2004). Solution for seepage beneath an impervious dam with sheetpile on a layered soil has been presented by Zheng-yi and Wu (2006) extensive analyses were performed for different conditions including dam width and sheetpile depth. Plastic concrete cutoff walls were constructed in a number of dam projects to control the seepage and to increase the safety of the structures (Dyer et al. 1988; Kahl et al. 1991). Exact analytical solution is required for seepage flow below dams with inclined cutoff located anywhere along the base of the dam. An exact solution has been obtained for seepage flow below a dam structure with inclined cutoff located anywhere along the base of the dam (Ijam 2011). The equations derived have been used for computation of pressures at key points and the hydraulic gradient along the downstream bed level. The results reveal that the pressure is reduced when the inclination of the cutoff is towards the downstream side of the dam. This increases the stability of the dam against sliding and decreases the possibility of tension stress development in the dam material.

In the study of Pakbaz et al. (2009), first the integrity of the plastic concrete cutoff wall in Karkheh dam is sought by reviewing constructional controls and observations. Then, the performance of the wall before the extension is modeled using SEEP 3-D computer code and calibrated using actual seepage measurements. The future performance of the wall when reservoir reaches its maximum level is also predicted.

Engineering geological properties of the ground at the Chapar-Abad Dam were investigated in order to evaluate seepage problems and to select a proper method of water-proofing prior to construction (Uromeihy and Barzegari 2007).

Yifeng et al. (2008) used a numerical solution based on the Finite Element Method combining the substructure technique with a variational inequality formulation of Signorini's type to solve relative equations. The aims of this work were to accurately characterize the boundary conditions of the drainage systems, to reduce the difficulty in mesh generation resulting from the drainage holes with small radius and dense spacing, and to eliminate the singularity at the seepage points and the resultant mesh dependency.
In this study the effects of different locations and angles of cutoff wall on exit gradient, seepage rate and uplift force would be assessed. For this purpose, a diversion dam within preamble foundation and cutoff beneath the dam is considered and simulated using Seep/w model. The variable design parameters are different longitudinal locations for cutoff wall and different angles for placement of it beneath the dam.

\section{Materials and Methods}

\subsection{Governing Equations}

Seepage discharge obeys Darcy's law (Eq. 1):

$Q=-K A(\partial h / \partial l)$

where $Q$ is seepage discharge (cubic meters per second), $K$ is hydraulic conductivity coefficient $(\mathrm{m} / \mathrm{s})$, $A$ is the cross sectional area $\left(\mathrm{m}^{2}\right)$ and $\partial h / \partial l$ is the flow hydraulic gradient. Poisson's equation is an equation of water flow in porous media which is the generalized form of Laplace well-known equation (Eq. 2):

$K_{x} \frac{\partial^{2} h}{\partial x^{2}}+K_{y} \frac{\partial^{2} h}{\partial y^{2}}=q$

where $K_{x}$ and $K_{y}$ are the coefficients of hydraulic conductivity in the $x$ and $y$ direction, respectively $(\mathrm{m} / \mathrm{s}), h$ is the total head (m) and $q$ is the discharge flow rate input/output to the soil (cubic meter per second per unit area, $\mathrm{m} / \mathrm{s}$ ).

Poisson's equation solution is one of the most complex mathematical problems and numerical methods help for solving differential equations and their conversion into a set of algebraic equations. Seep/w is software to solve Poisson's equation by the finite element method.

\subsection{Numerical simulation method}

In this study, a diversion dam within given size is considered as in Fig. 1. Assumed boundary conditions are: $35 \mathrm{~m}$ of potential head in upstream and $25 \mathrm{~m}$ of potential head in downstream of the diversion dam. Bottom, right and left walls of foundation and also bottom of diversion dam is assumed as impervious, which is considered as the base model. Calculation of seepage rate and exit gradient in all conditions are 


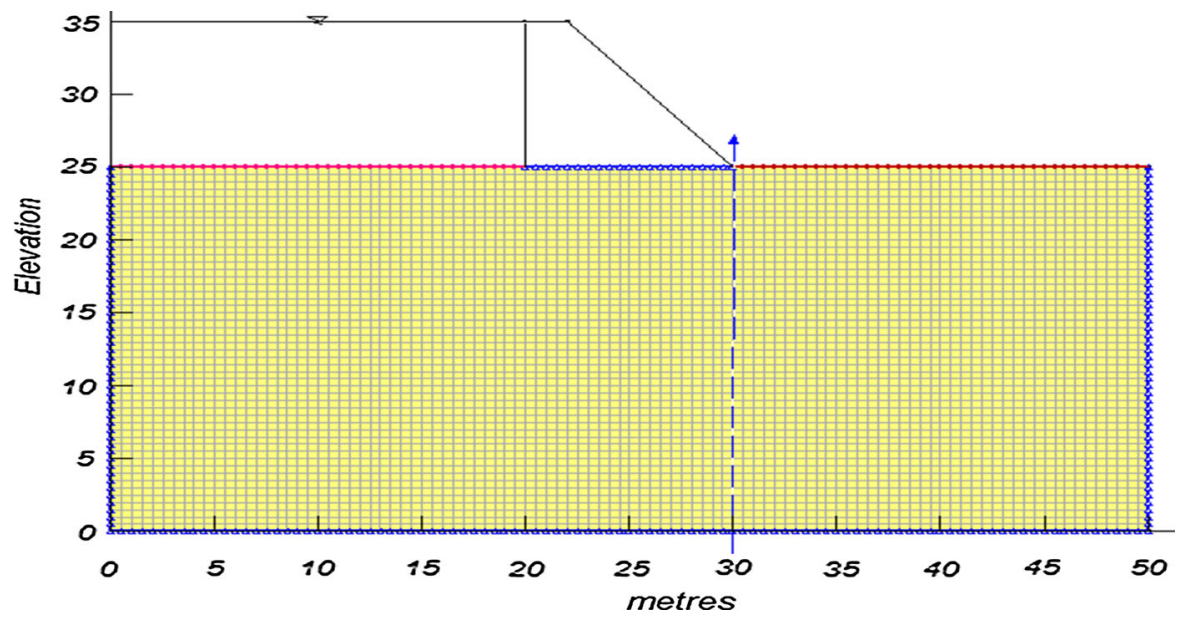

Fig. 1 Assumed cross-section of the diversion dam (base model)

Table 1 Permeability of materials used in dam

\begin{tabular}{ll}
\hline$K_{\text {sat }}(\mathrm{m} / \mathrm{s})$ & Materials \\
\hline $10^{-9}$ & Cutoff wall \\
$10^{-5}$ & Foundation \\
\hline
\end{tabular}

solved by finite element method using Seep/w model; a part of Geo-Studio 2007 software package (Anonymous 2007).

Total number of the 2D elements used in model is 3,012. Permeability of the cutoff wall and dam's foundation are described in Table 1 . Ratio of $K_{x} / K_{y}$ was selected equal to 1.0 (soil considered to be isotropic). Figure 2 is provided for a better understanding of sizes.

In addition to numerical simulation of the base model (Fig. 1), 10 other models are considered. So the ratios of the placement distance of cutoff wall from upstream of diversion dam to length of the dam $\left(b_{1} / b\right)$ are respectively equals to $0,0.1,0.2,0.3,0.4,0.5,0.6,0.7,0.8$, and 0.9. In addition, the depths of cutoff wall are considered $12 \mathrm{~m}$ and the thickness is considered $0.5 \mathrm{~m}$. The point $E$ is joint point of cutoff wall with dam.

For example, cutoff location in relative position of 0.2 from upstream $\left(b_{1} / b=0.2\right)$ has been presented in Fig. 3. As it is clear in Fig. 3, in the places that need more accuracy (around of cutoff wall) smaller elements are used.

In next phase of this study, effects of the different angles of cutoff placement would be compared. For this purpose, the angles of $10^{\circ}, 20^{\circ}, 30^{\circ}, 40^{\circ}, 50^{\circ}$, and $60^{\circ}$ (respect to vertical) for cutoff relative placements of $0,0.2,0.4,0.6$, and 0.8 from upstream are considered.
Fig. 2 Definition of geometrical parameters

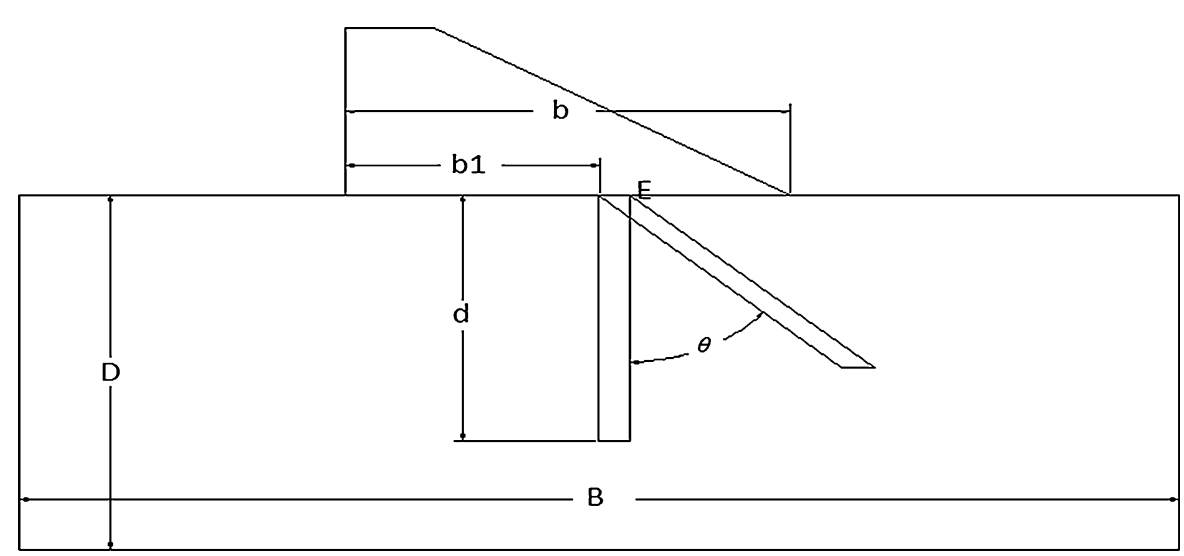


Fig. 3 Cross-section of diversion dam in relative position of 0.2 from upstream within $12 \mathrm{~m}$ of cutoff wall depth
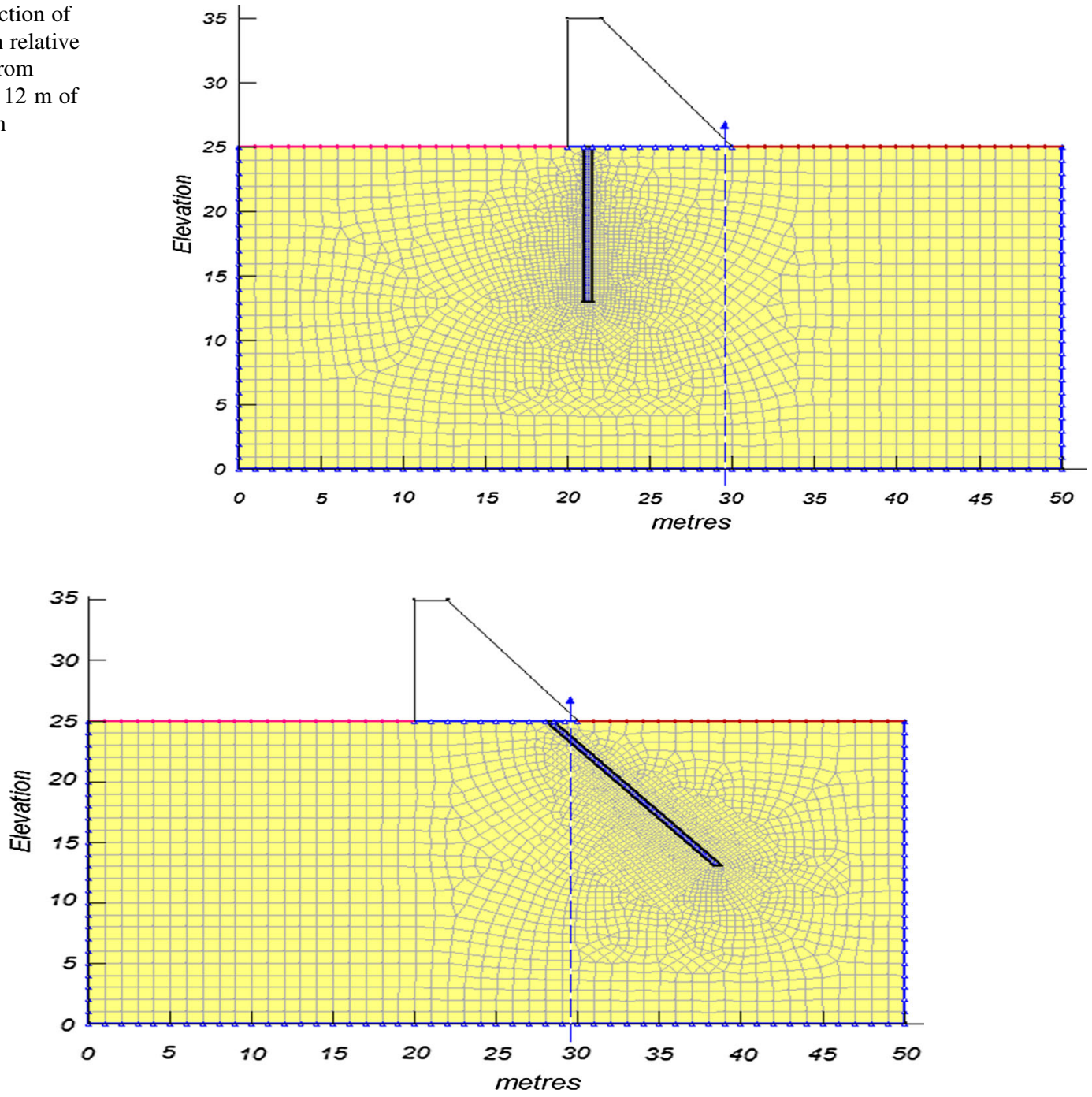

Fig. 4 Cross-section of diversion dam within $60^{\circ}$ of cutoff and relative position of 0.9 from the upstream

For example in Fig. 4, a cutoff wall placement at angle of $60^{\circ}$ and in a relative position of 0.9 from upstream is shown.

\section{Results and Discussion}

In order for studying the effects of various angles of cutoff placement on seepage rate, exit gradient, and uplift force, several relative positions of $0.0,0.1,0.2$, $0.3,0.4,0.5,0.6,0.7,0.8$, and 0.9 are considered for comparison. All cross sections for determining of

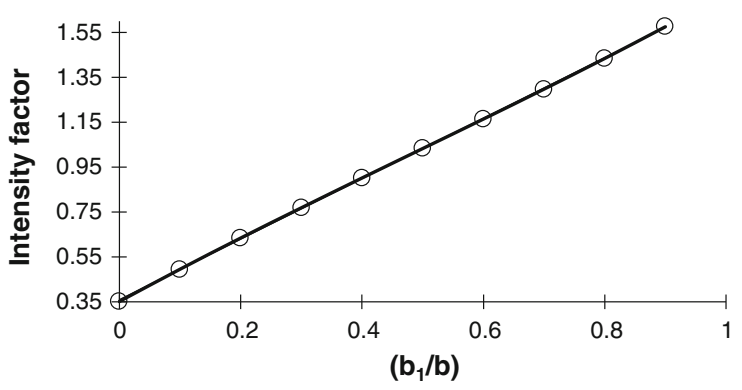

Fig. 5 Effect of relative cutoff wall position $\left(b_{1} / b\right)$ on uplift force 
Fig. 6 Equipotential lines for cross-section of the base model of dam (without cutoff)

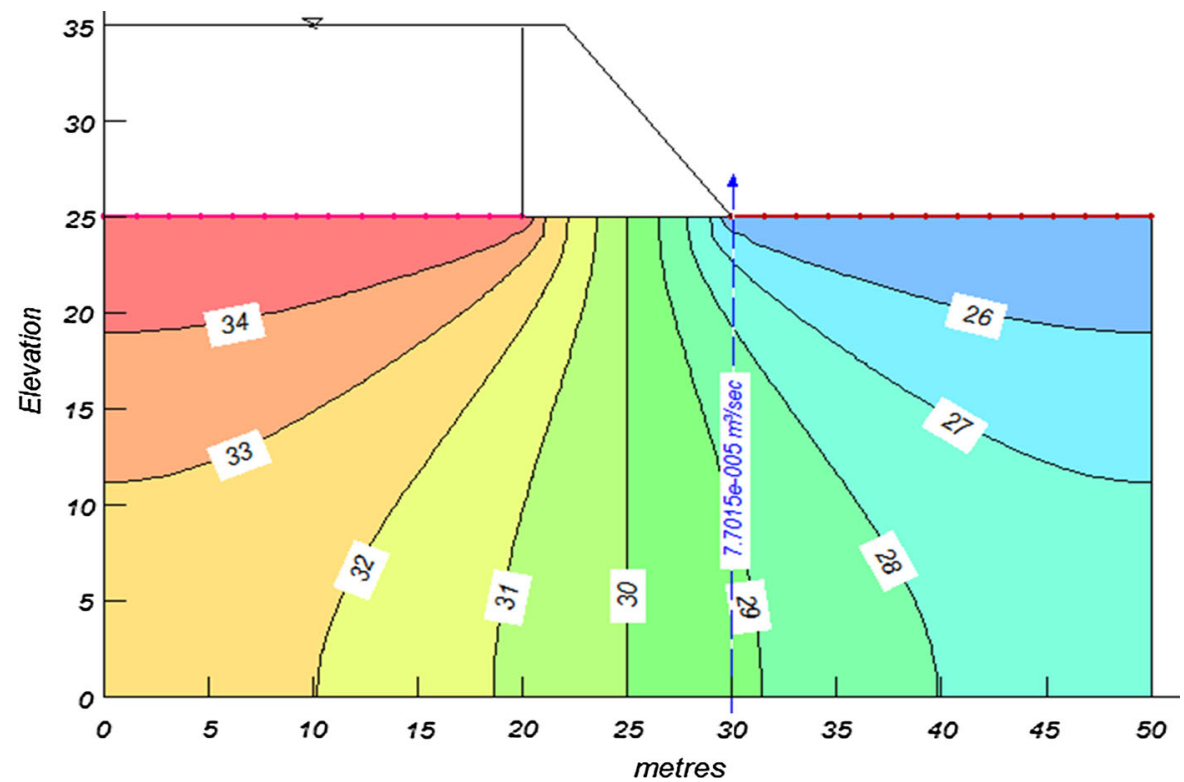

seepage flow would be in position which has $29.5 \mathrm{~m}$ distance from upstream of the dam. In Fig. 5 the results of numerical simulation for uplift force are showed. In Fig. 5, intensity factor (in vertical axis) is the ratio of total uplift force to the total uplift force in the base model (without cutoff wall as in Fig. 1).

According to Fig. 5, it is clear that the minimum value of uplift force is for the condition that cutoff is at upstream and the maximum is at the end of the dam. So that, it can be expressed that the best place for cutoff in order to decrease uplift force is at upstream (heel) of the dam. In heel of the dam, intensity factor is 0.35 . In the other words, the upstream cutoff causes decrement 0.75 in uplift forces respect to the condition that no cutoff wall used. According to Fig. 5, how much the cutoff wall gets away from upstream/heel, the intensity factor would increase linearly $(\mathrm{y}=1.3475 \mathrm{x}+$ $0.3599, x$ is relative position of cutoff and $y$ is the intensity factor, $\mathrm{R}^{2}=0.9999$ ).

It should be stressed that all results and the analysis refer to the specific ratio of the cutoff to the total thickness of the permeable layer $(12 / 25=0.48)$ and results are expected to change and maybe considerably if the above ratio gets high values.

For example, both base model and the model within 12 meters of cutoff wall depth in relative position of 0.3 form upstream are showed in Figs. 6 and 7. Equipotential lines and seepage amount are showed in both conditions too.
According to Figs. 6 and 7, it could be observed that the total head in condition that cutoff wall is used, have more loss respect to the base model without cut off, which is an explainer to uplift force decrement. This could assure the dam's stability even more. Also within an accurate look to the Figs. 6 and 7, it is observable that by using the cutoff, seepage rate would decrease dramatically.

In Fig. 8 the numerical simulation for exit gradient has been conducted. Additionally the vertical axis of Fig. 8 is the ratio of exit gradient to the exit gradient of the base model.

According to Fig. 8, the minimum value of exit gradient is for condition that the cutoff wall is at the end of the dam and the maximum value of that is for the condition that cutoff is in upstream of dam. As a result, it can be expressed that the best placement for cutoff wall in order to decrease exit gradient is the downstream of dam. The more cutoff wall gets far form upstream heel of the dam, the more parabolic decrement on exit hydraulic gradient ratio would be observed. Nonetheless the exit gradient value in all conditions are less than critical value $(i=1)$ and they do not expose dam to risk. Within prepending on Fig. 8, it could be figured out that in relative position of 0.5 to the downstream of dam, the exit gradient would have a sharp decrement. So whenever a dangerous hydraulic gradient in a project occurs it is recommended to place cutoff wall in relative position range of 0.5 to downstream of dam. 
Fig. 7 Equipotential lines for the cross-section of the model within a 12 m cutoff depth in relative position of 0.3 from the upstream
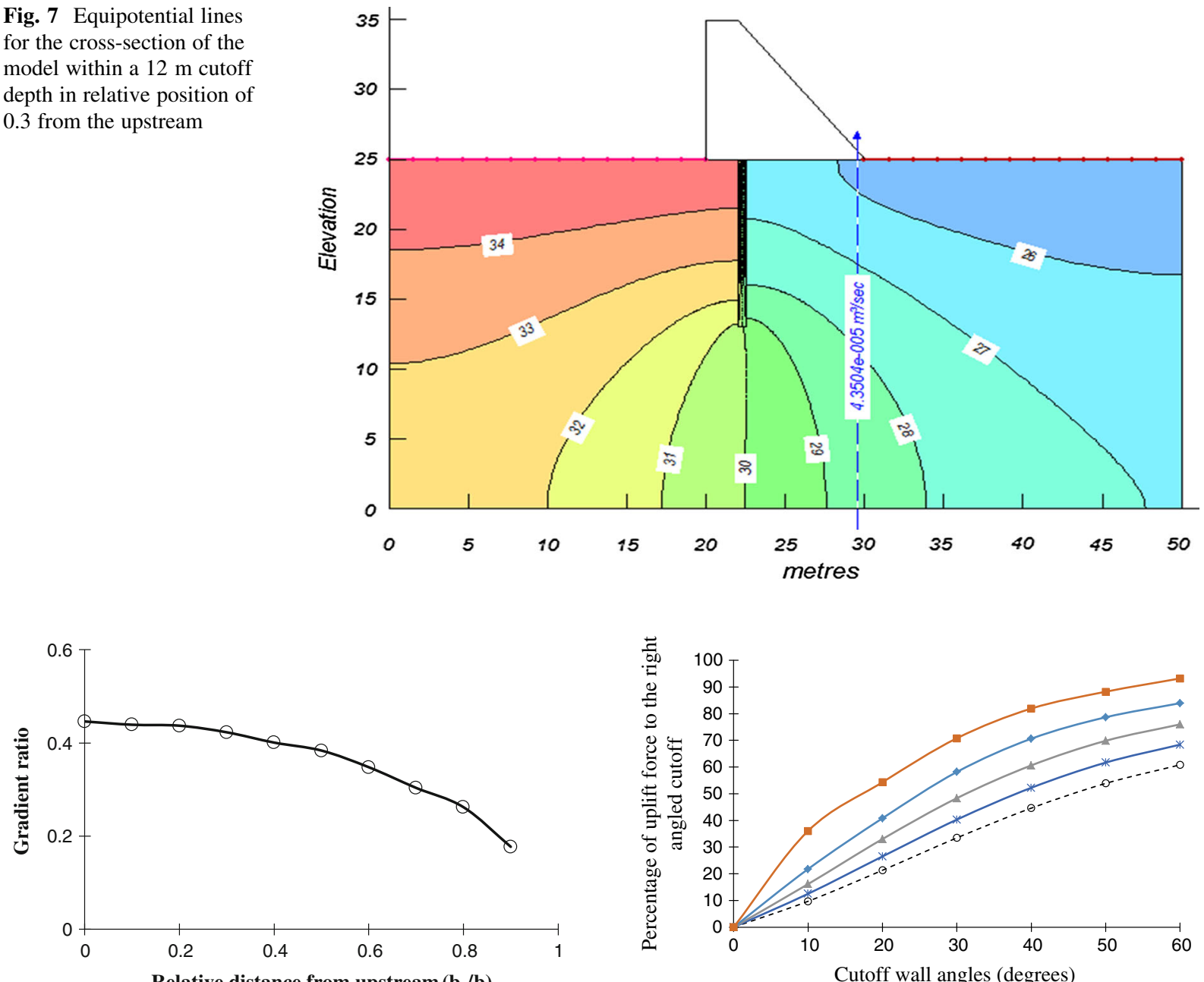

Fig. 8 Effect of cutoff position on exit hydraulic gradient

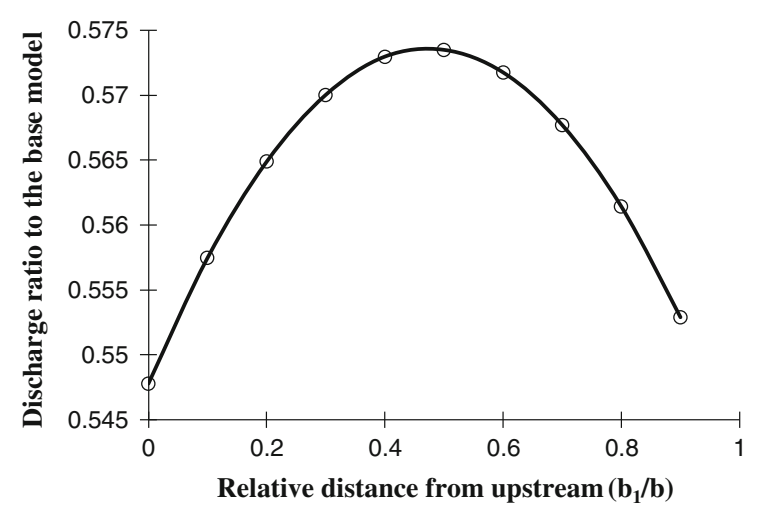

Fig. 9 Effect of cutoff position on the seepage

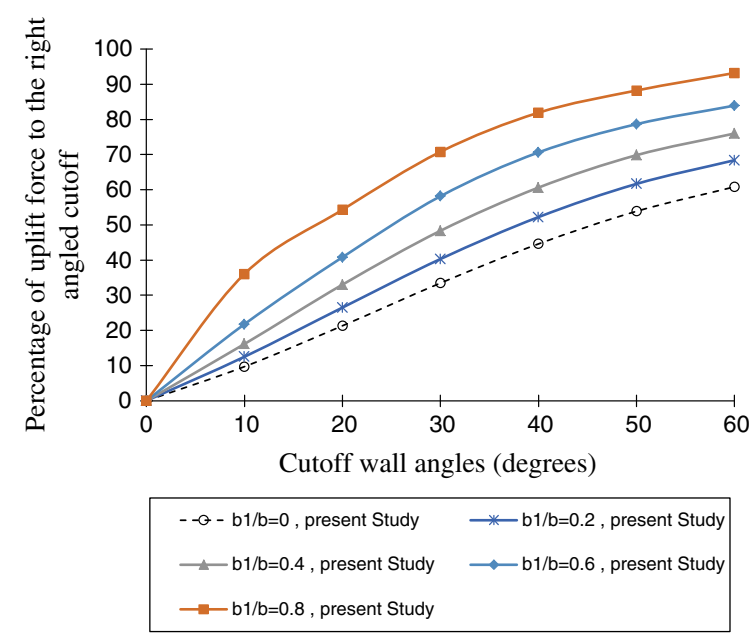

Fig. 10 Comparison of the effects of the location and the angle of the cutoff wall for uplift force of point $E$ to the condition right angled cutoff wall

In Fig. 9 the results form numerical simulation for foundation seepage discharge are presented. Additionally the vertical axis in Fig. 9 is the ratio of seepage to the base model's seepage discharge.

According to Fig. 9, in all cutoff placement positions, a remarkable discharge decrement would be observed. Also within placing the cutoff at the range of relative positions $0-0.5$ from upstream, a parabolic increment in discharge would occur and at the range of relative position 0.5 to the downstream similarly 


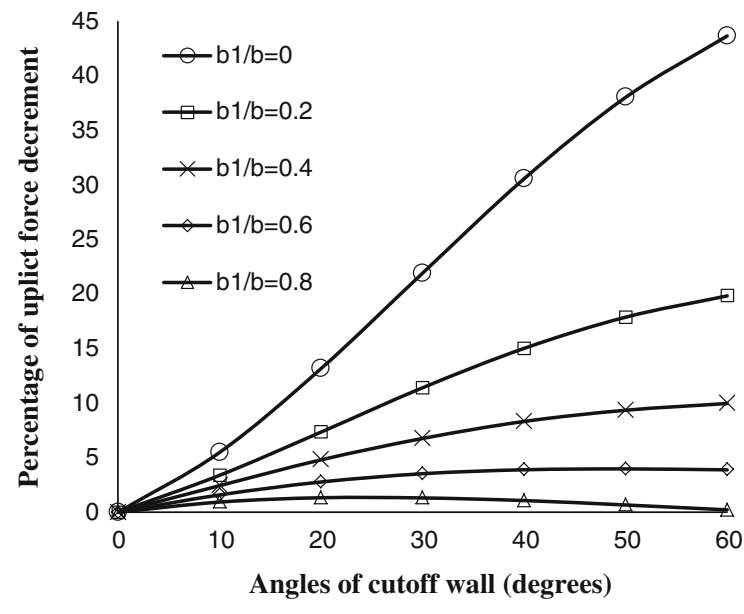

Fig. 11 Comparison of total uplift force on the different angles of cutoff wall to the right angled condition

decrement would occur. Cutoff placement on upstream or downstream results in minimum discharge value and placement in the middle of dam would result in maximum discharge.

In next phase for studying of the different angles of cutoff wall on uplift force, the positions of $0,0.2,0.4$, 0.6 , and 0.8 are considered within angles of $10^{\circ}, 20^{\circ}$, $30^{\circ}, 40^{\circ}, 50^{\circ}$, and $60^{\circ}$ for each one.

In Fig. 10, the results of numerical simulation for uplift force are presented. In addition, the horizontal axis of Fig. 10 is the angles of cutoff wall and the vertical one is the percentage of uplift force to the right angled cutoff wall condition.

According to Fig. 10, in a constant cutoff wall relative position from upstream, within angle increment the uplift force in point $E$ would decrease. The closer cutoff wall places to the downstream heel and the more angled cutoff wall places the lower uplift force in point $E$ would be expected. In this regard, the percentage of uplift force decrement in point $E$, within increasing the angle on positions near to upstream heel would shape like straight line, bus on positions near to downstream heel of dam it would shape parabolic.

In Fig. 11 comparison of total uplift force on the different angles of cutoff wall to the right angled condition is presented.

Figure 11 shows that when cutoff wall placed near to downstream heel, within angle increment the percentage of total uplift force decrement would decrease. It means that the total uplift force on position near to the downstream heel would be more than the other models, which has a correspondence to the Fig. 5. This decrement percentage of total uplift force, within angle increment on positions near the upstream of dam would have bigger increment and on positions near to the downstream of dam would decrease the intensity of it (total uplift force decrement percentage).

For example the right angled cutoff wall and the cutoff within angle of $60^{\circ}$ are presented in
Fig. 12 Equipotential lines for right angled condition of cutoff wall in upstream

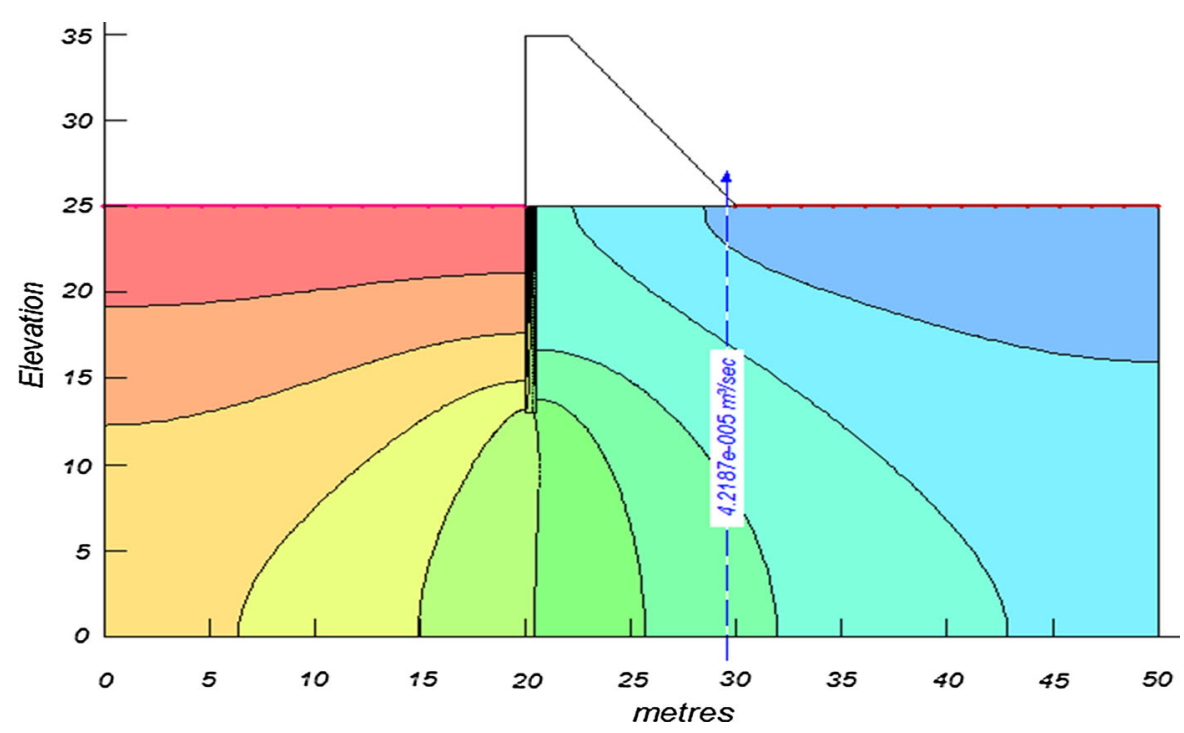


Fig. 13 Equipotential lines of the cutoff wall for $60^{\circ}$ condition on upstream

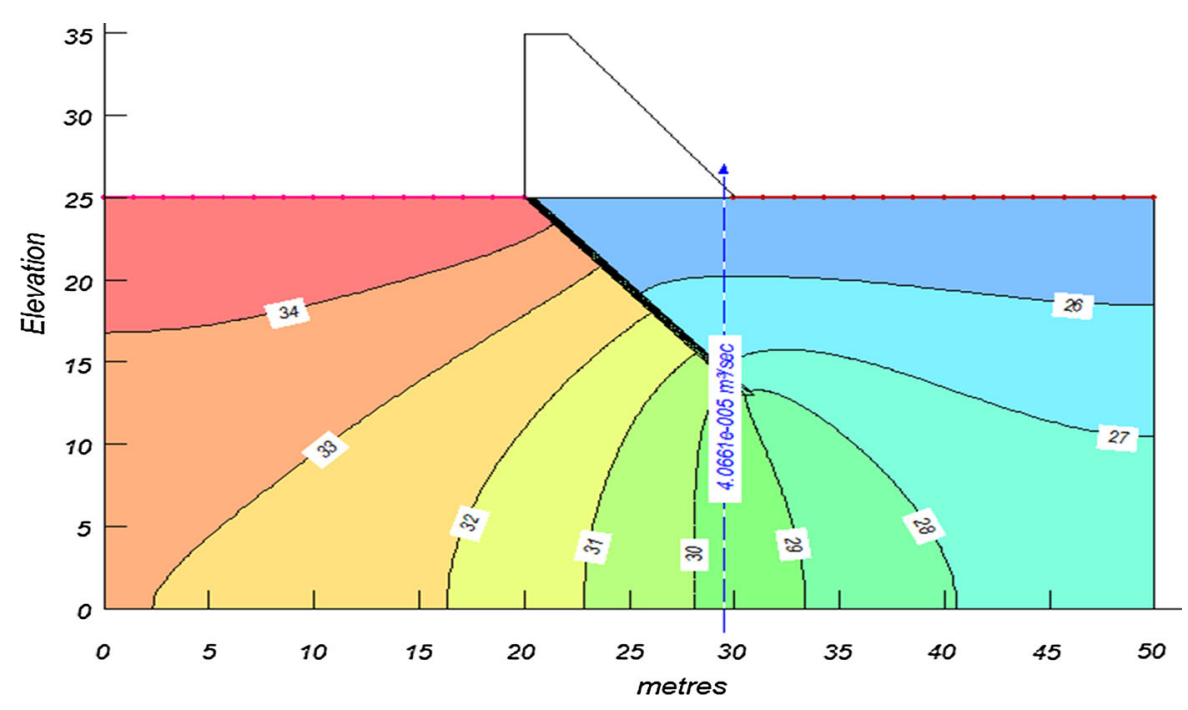

Figs. 12 and 13. In Figs. 12 and 13 equipotential lines and seepage discharges are presented.

As can be seen in Figs. 12 and 13 equipotential lines on upstream heel, in angled condition shows remarkable head loss comparison to the right angled model. So that it shows the lower uplift force compared to the base model. This provides more stability for dam. Also within exact look at Figs. 12 and 13 the seepage discharge with angled cutoff wall would be lower than the right angled condition.

\section{Conclusion}

The major contribution of this paper is to compare the efficiency of cutoff wall on some design parameters in an assumed diversion dam cross-section. The different placements of cutoff wall with various angle of inclination were used in dam foundation. Analyses are based on finite elements. It should be stressed that all results and the analysis refer to the specific ratio of the cutoff to the total thickness of the permeable layer $(12 / 25=0.48)$ and results are expected to change and maybe considerably if the above ratio gets high values. Results showed that:

- The minimum total uplift force and maximum exit gradient would occur when the cutoff wall places on upstream of dam and vice versa.

- Within using cutoff wall, a remarkable decrement in seepage would occur, on conditions that cutoff wall places upstream heel or downstream heel of dam the minimum seepage discharge would be observed and the maximum seepage discharge occur when the cutoff wall places in the middle of the dam.

- When the cutoff wall gets close to downstream heel of dam and when the placement angle gets more, the uplift force decrement percentage of the point $E$ would increase and total uplift force decrement percentage would decrease.

Open Access This article is distributed under the terms of the Creative Commons Attribution License which permits any use, distribution, and reproduction in any medium, provided the original author(s) and the source are credited.

\section{References}

Anonymous (2007) Seepage modeling with SEEP/W. An engineering methodology. Third edition, March 2008. GEO-SLOPE International Ltd, Calgary

Di Cervia AR (2004) Construction of the deep cutoff at the Walter F. George Dam, Geosupport conference, Orlando, Florida, USA

Dyer D, Fanning B (1988) Wolf Creek dam-concrete diaphragm walls, Final completion reports, Defence Technical Information Center, USA

Harr ME (1962) Groundwater and seepage. McGraw-Hill Inc., USA

Ijam AZ (1994) Conformal analysis of seepage below a hydraulic structure with inclined cutoff. Int J Numer Anal Methods Geomech 18(5):123-135

Ijam AZ (2011) Dams with an inclined cutoff. J EJGE 16(1):1427-1440 
Kahl TW, Kauschinger JL, Perry EB (1991) Plastic concrete cutoff walls for earth dams, Technical Rept. REMR-GT15, Waterways Experiment Station

Pakbaz MS, Dardaei A, Salahshoor J (2009) Evaluation of performance of plastic concert cutoff wall in Karkheh dam using 3-D seepage analysis and measurement. J Appl Sci 9(4):724-730

Uromeihy A, Barzegari G (2007) Evaluation and treatment of seepage problems at Chapar-Abad Dam, Iran. J Eng Geol 91:219-228
Yifeng C, Chuangbing Z, Hong Z (2008) A numerical solution to seepage problems with complex drainage systems. Comput Geotech 35(3):383-393

Zheng-yi F, Wu JTH (2006) The epsilon method: analysis of seepage beneath an impervious dam with sheet pile on a layered soil. Can Geotech J 43:87-96 